\title{
What Indigestion Means to the Malays?
}

\author{
Yeong Yeh Lee ${ }^{1 *}$ and Andrew Seng Boon Chua ${ }^{2}$ \\ ${ }^{1}$ Department of Medicine, School of Medical Sciences, University Sains Malaysia, Kubang Kerian, Kelantan, Malaysia; and ${ }^{2}$ Gastro Center Ipoh, \\ Ipoh, Perak, Malaysia
}

Despite being a large ethnic group within the South-East Asia, there is a paucity of reported literatures on dyspepsia in the Malay population. Recent population-based studies indicate that uninvestigated dyspepsia, based on the Rome II criteria, is reported in $12.8 \%$ and $11.6 \%$ of Malays in the urban and rural communities respectively. Organic causes of dyspepsia including upper gastrointestinal tract cancers, its precancerous lesions, and erosive diseases are uncommon which is largely due to an exceptionally low prevalence of Helicobacter pylori infection in this population. On the other hand, functional dyspepsia and irritable bowel syndrome are relatively common in the Malays than expected. Within a primary care setting, functional dyspepsia, based on the Rome III criteria, is reported in 11.9\% of Malays, of which epigastric pain syndrome is found to be more common. Married Malay females are more likely to have functional dyspepsia and psychosocial alarm symptoms. Also based on the Rome III criteria, irritable bowel syndrome, commonly overlapped with functional dyspepsia, is reported in $10.9 \%$ of Malays within a community-based setting. Rather than psychosocial symptoms, red flags are most likely to be reported among the Malays with irritable bowel syndrome despite having a low yield for organic diseases. Based upon the above observations, "proton pump inhibitor test" is probably preferable than the "test and treat H. pylori" strategy in the initial management of dyspepsia among the Malays.

(J Neurogastroenterol Motil 2013;19:295-300)

Key Words

Dyspepsia; Functional dyspepsia; Irritable bowel syndrome; Malaysia

\section{Introduction}

Dyspepsia, a symptom complex centered in the upper abdomen, is a widely known term among clinicians, however, patients often have a variable and inconsistent interpretation of it. Even the commonly used lay term in English, 'indigestion' is often vague, encompassing a multitude of poorly defined ills anywhere in the upper abdomen. Other non-English speaking populations may not have a similar lay term to describe their upper abdominal ills, and this may account for the wide range of prevalence rates reported. ${ }^{1}$

South-East Asia is a cultural-diverse region rich with multiple ethnics and indigenous communities. One of the larger ethnic groups is the Malays (Melayu) who are a member of the Austronesian family, largely populating the Peninsular Malaysia, Sumatra and Borneo. ${ }^{2}$ The Malay language, has its origin from the an-

Received: April 5, 2013 Revised: May 10, 2013 Accepted: May 12, 2013

(c) This is an Open Access article distributed under the terms of the Creative Commons Attribution Non-Commercial License (http://creativecommons. org/licenses/by-nc/3.0) which permits unrestricted non-commercial use, distribution, and reproduction in any medium, provided the original work is properly cited.

*Correspondence: Yeong Yeh Lee, MD, FRCP, FACP

School of Medical Sciences, University Sains Malaysia, 16150 Kubang Kerian, Kelantan, Malaysia

Tel: +609-7663000, Fax: +609-7648277, E-mail: justnleeyy@gmail.com

Financial support: We thank the South East Asia Gastro-Neuro Motility Association (SEAGMA) and Malaysian Society of Gastroenterology and Hepatology (MSGH) for funding some of the studies mentioned in the article.

Conflicts of interest: None (The paper has been presented in part during the 3rd biennial congress of the Asian Neurogastroenterology and Motility Association 2013 held in Penang, Malaysia).

Author contributions: Yeong Yeh Lee and Andrew Seng Boon Chua were involved in providing ideas, design, analysis and writing of manuscript. 
cient Austronesian language, is one of the world most spoken language, being spoken by approximately 180 million people. ${ }^{3}$

Despite being a large ethnic group within the South-East Asia, there is a paucity of reported literatures on dyspepsia in the Malay population. The current review examined unique characteristics of dyspepsia among the ethnic Malays.

\section{Uninvestigated Dyspepsia}

This refers to patients who report dyspeptic symptoms but did not undergo investigations to rule out upper gastrointestinal diseases, including peptic ulcer disease and gastric cancer. Available studies from Asia suggest a frequency of uninvestigated dyspepsia to be between $8-30 \%$, which is clearly variable between different ethnics. ${ }^{4}$ In a cross-sectional survey involving 2,039 multiracial urban population in Malaysia (city of Kuala Lumpur), uninvestigated dyspepsia using the Rome II criteria was reported in $24.3 \%$ of adults. ${ }^{5}$ Ethnic Malays comprised $45.3 \%$ of the studied urban population and dyspepsia was reported in 12.8\%. Among studied risk factors, $56.8 \%$ of the Malays had moderate to heavy consumption of chili, $15.7 \%$ of the Malays consumed analgesic and only $19.6 \%$ had chronic illnesses. A similar cross- sectional survey was performed in 2,000 rural population in Malaysia (Kuala Langat, Selangor), of which uninvestigated dyspepsia using the Rome II criteria was reported in $14.6 \%$ of adults. ${ }^{6}$ Ethnic Malays comprise $79 \%$ of studied rural population and dyspepsia was reported in $11.6 \%$. There was no significant gender difference (females $15.8 \%$ vs. males $12.7 \%$ ) with or without dyspepsia. Higher levels of education (secondary and tertiary) and non-village type housing were found to be associated with a higher risk for dyspepsia and regular tea drinking appeared to be protective. The rural population frequently reported a lower health-related quality of life but the economic impact of dyspepsia was greater in the urban population. ${ }^{6,7}$ Rural Malays commonly under-report dyspepsia to their doctors and tend to self-medicate. ${ }^{8}$ The level of medical services including endoscopy that is considerably lower in the rural community may be partly responsible for under-reporting.

\section{Organic Causes of Dyspepsia Are Uncommon Among Malays}

\section{Helicobacter pylori Infection}

Helicobacter pylori infection is responsible for many causes of organic dyspepsia, in particular peptic ulcer disease and gastric cancer, with important public health consequences. Despite being common among the populations in the Asia Pacific, ethnic Malays are surprisingly spared from this infection. Before the discovery of $H$. pylori in 1982, in the first half of the 20th century, it was already noted that peptic ulcer and gastric cancer were rare in the ethnic Malays but not in the Chinese or Indian populations living in this region. ${ }^{9}$ In a pediatric clinic in Medan, Sumatra, of 874 patients, only $6.5 \%$ complained of abdominal pain and $5.5 \%$ of abdominal distension. ${ }^{10}$ Studies from Singapore also found that the ethnic Malays were under-represented in dyspepsia of any cause in a series of 2,277 patients. ${ }^{11}$

With the first report of $H$. pylori infection in Malaysia, ${ }^{12}$ subsequent studies confirmed that the ethnic Malays have a lower prevalence of $H$. pylori infection compared to the Chinese or the Indian populations (termed the "racial cohort phenomenon"). ${ }^{13}$ The ethnic Malays from the northeastern region of Peninsular Malaysia (state of Kelantan), comprising $90 \%$ of its demography, have probably the lowest reported prevalence of $H$. pylori in the world besides the Pemba Island in Zanzibar. ${ }^{14-17}$ The H. pylori sero-prevalence rate in this region ${ }^{14}$ has been reported to be only $4.2 \%$ among blood donors and this is in contrast with $11.9 \%$ among blood donors in the Klang valley ${ }^{13}$ where the population consists of the Malays of $30 \%$ and $15.2 \%$ among blood donors in the northwestern region ${ }^{18}$ of the Peninsular where the population consists of the Malays of $20 \%$. The above difference in sero-prevalence rates between regions is explained by transmission from $H$. pylori-infected non-Malay immigrants to the non-infected Malays.

The reasons, underlying the low prevalence of $H$. pylori infection among the Malays, remain elusive. ${ }^{19}$ One possibility is that local practices or environmental factors may limit transmission or inhibit the infection. In a case-control study involving 161 Malay subjects (79 tested positive for $H$. pylori or "cases" and 82 tested negative for $H$. pylori or 'controls') from the state of Kelantan, some dietary factors were found to reduce risk of infection including frequent use of 'budu,' 'pegaga or Centenella asiatica' and tea. ${ }^{20}$ Unidentified genetic or host factors intrinsic to this population may also result in them being less or have increased susceptibility to $H$. pylori infection or cancer as a whole. In a recent study, protective gene variants were found among ethnic Malays residing in Kelantan including C7orf10, TSTD2, $S M G 7$ and $X P A .^{21}$ These genes encode enzymes involved in metabolism of compounds which are inhibitory to the survival of $H$. pylori bacterium as well as proteins that allow detection and repair of aberrant genomes. However, polymorphism in the Deleted in 
Colorectal Cancer (DCC) gene (rs 10502974) was associated with increased risk of H. pylori infection in the Malays. ${ }^{22}$

\section{Upper Gastrointestinal Cancers and Its Precursors}

Dyspepsia is one symptom of upper gastrointestinal cancers, often accompanied by alarm features. Due to an exceptionally low prevalence of $H$. pylori among the Malays, gastric cancer and its precancerous lesions are also rare. The incidence of gastric cancer according to the Malaysian National Cancer Registry for the period between 2003-2005 was 2.2/100,000 among the Malays and was lower compared to the Chinese $(11.3 / 100,000)$ and the Indians $(11.9 / 100,000){ }^{23}$ In a survey of 234 subjects undergoing upper endoscopy in a tertiary hospital from the state of Kelantan, the overall reported rate of atrophic gastritis was $42.3 \%$ (99/234) and that of intestinal metaplasia was $7.7 \%(14 / 234) .{ }^{24}$ Notably intestinal metaplasia was only present in $1.4 \%(2 / 146)$ of Malay subjects. The low rate of atrophic gastritis and intestinal metaplasia in the above study was a result of low $H$. pylori infection in the study population of only $6.8 \% .^{24}$ More recently, certain gene variants are found to be associated with gastric precancerous lesions in this Malay population, and these gene variants, rs9315542 (UFM1 gene), rs6878265 (THBS4 gene), rs1042194 (CYP2C19 gene) and rs10505799 (MGST1 gene) were associated with atrophic gastritis, complete intestinal metaplasia, incomplete metaplasia with foci of dysplasia and only dysplasia, respectively. ${ }^{25}$

In contrary to beliefs of some investigator, based on the hypothesis that eradication of $H$. pylori may result in an increase in the incidence of gastroesophageal reflux disease and therefore esophageal cancer, the age-standardized incidence for esophageal cancer among ethnic Malays from Kelantan was only 1.6/100,000 in males and 2.2/100,000 in females. ${ }^{26}$ Likewise, in a retrospective study involving 1,895 consecutive patients undergoing upper endoscopy between 2005 and 2007 in a tertiary hospital in Kelantan, only $0.8 \%$ of patients had Barrett's esophagus. ${ }^{27}$ The reported rates for Barrett's esophagus are much higher among patients undergoing endoscopy from the northwestern region and the Klang valley of Peninsular Malaysia being $6.2 \%$ and $2.0 \%$ respectively. $^{27}$

\section{Gastroduodenal Diseases and Erosive Esophagitis}

Early studies from Malaysia indicate that the incidence of peptic ulcers and perforated ulcers were less common among the
Malays, as compared to the Chinese and the Indians. ${ }^{28}$ Similarly, non-erosive reflux disease and erosive esophagitis remained uncommon in the Malay population, despite a rising trend being observed elsewhere in the region and around the world. ${ }^{29,30}$ In a recent report, clinically significant endoscopic findings, defined as endoscopic pathologies that accounted for symptoms of dyspepsia, were found in $26.4 \%$ of Malaysian adults $(6.8 \%$ in the Malays) with uninvestigated dyspepsia, with risk factors being age $\geq 45$ years, male gender, $H$. pylori infection and duration of dyspepsia $\leq 5$ months. ${ }^{31}$ In this study, peptic ulcer disease was found to be more prevalent in the Chinese population and erosive esophagitis in the Indians, but both diseases were not common among the Malays. ${ }^{31}$

\section{Functional Causes of Dyspepsia Are Common in Malays}

\section{Rome III Criteria of Dyspepsia}

Previously known as non-ulcer dyspepsia, functional dyspepsia (FD), defined by Rome III, is essentially chronic dyspepsia after exclusion of organic diseases. ${ }^{32}$ In the majority of patients presenting with dyspepsia, often, no underlying organic cause can be identified. ${ }^{5}$ A true prevalence of FD in the general population is however often difficult to determine, but available data from Asia indicate that the prevalence is in the range between $11 \%$ and $29 \%$, depending on whether the Rome criteria is used or not. ${ }^{33}$ Furthermore, in actual practice, both heartburn and dyspepsia are not easily distinguished from each other, if based on symptoms alone, since overlap frequently exists between the two. ${ }^{34}$ Likewise, symptoms of irritable bowel syndrome (IBS) frequently coexist with FD, especially in the context of Asia, where patients with IBS tend to report upper abdominal symptoms together. ${ }^{35}$

There are 4 major symptoms that characterize FD in Rome III, namely, early satiation, postprandial fullness, epigastric pain and epigastric burning, among some of which considerable confusion exists when translated into other languages. ${ }^{32}$ There have been limited studies on cross-cultural translation of Rome III questionnaires but there are ongoing efforts encouraged by the Rome foundation. Both the Rome III Diagnostic Questionnaires for IBS and FD have been translated into the Malay language, with the IBS module showing reliable psychometric properties during its validation. ${ }^{36}$ Likewise, the Red Flag and Psychosocial Alarm questionnaires have been translated into the Malay lan- 
guage, although not diagnostic, they are helpful in identifying alarm symptoms, which may alert physicians for further investigations if needed. ${ }^{36}$ During the translation process, in particular during reconciliation, it is desirable that physicians are involved alongside linguistic experts, and both should be familiar with local nuances. The symptom of fullness and bloating can be particularly challenging during translation with variations regarding especially of its quality, site and severity.

\section{Functional Dyspepsia}

The role of $H$. pylori infection in FD has remained unclear. ${ }^{37}$ Improvement of dyspeptic symptoms has been reported in non-ulcer dyspepsia with eradication of $H$. pylori, especially in the Chinese population but less so in the Western population. ${ }^{38}$ Part of the problem is that many subjects with non-ulcer dyspepsia might have overlapping $H$. pylori-associated gastritis, which upon eradication leads to some symptom improvement, but true functional symptoms remain. If $H$. pylori infection is contributory to FD, then population with low prevalence of $H$. pylori infection would have reported lesser dyspeptic symptoms, which is apparently not, among the ethnic Malays.

In a cross-sectional survey involving 160 Malay subjects attending primary care clinic in the northeastern region of Peninsular Malaysia, $11.9 \%$ fulfilled the Rome III criteria for FD. ${ }^{39}$ Approximately $2 \%$ of subjects were found to have erosive diseases from upper endoscopy but none of the subjects had $H$. pylori infection. This study indicates that FD is more common among the Malays than expected despite the extremely low prevalence of H. pylori in this population. A positive married status (odds ratio 8.1) and positive psychosocial alarm symptoms (odds ratio 3.8) were independent risk factors associated with FD. Of those married subjects, females were more likely to have FD and psychosocial symptoms than men. The reasons were likely to be due to a higher divorce rate and the Malay females being the breadwinner rather than men in this region. Of the 2 meal-related syndromes, epigastric pain syndrome (EPS) was found in $68.8 \%$ of subjects, especially among married females, and the rest had overlapping postprandial distress syndrome. This was similar to the Muslim population from Pakistan, raising the question, whether if the suppressed role of Muslim females might have played a role. ${ }^{40}$ Furthermore, in the current study, it was found that subjects with FD were more likely obese, which might mean that those with EPS could have gastroesophageal reflux disease. Considering the rather uncommon prevalence of reflux disease in this population, the effect of overlap of gastroesophageal reflux with FD is likely to be small, but further studies are needed to address this. This study also suggests that $H$. pylori infection is rather a surrogate factor of FD and psychological factors are likely to be more important in its pathogenesis.

\section{Irritable Bowel Syndrome}

In a group of 533 (the Malays of $52.2 \%$ or 278 subjects) multi-ethnic medical students within the Klang Valley of Peninsular Malaysia, $15.8 \%$ of them (the Malays of $15.8 \%$ or 44 subjects) were reported to have IBS based upon the Rome I criteria. $^{41}$ This urban population from a well-developed economic region was rather young (mean age $22 \pm 1.8$ years), well-educated and without any chronic illnesses. With such characteristics, it is probably not surprising for this group of population to be prevalent in IBS, similar to previous reports. ${ }^{42}$ In another study involving 949 (the Malays of $33.1 \%$ or 314 subjects) multi-ethnic subjects, of mixed urban and rural populations, from the northwestern region of Peninsular Malaysia, based on Rome II criteria, IBS was reported in $15.5 \%$ (the Malays of $12.4 \%$ or 39 subjects). ${ }^{43}$ Still part of an economically developed area of the Peninsular, this group of population is relatively older (mean age $33.6 \pm 13$ years) and contains a mix of rural population. Among 221 ethnic Malays (mean age $37.7 \pm 15.7$ years), of mixed urban and rural population, from the state of Kelantan, IBS was reported in $10.9 \%$ based upon Rome III criteria. ${ }^{44}$ This population was relatively older, had lower socioeconomic power and less educated compared to those Malays in the west coast of the Peninsular. While these studies are community-based rather than population-based, and despite the differences in Rome criteria and socioeconomic status, the prevalence of IBS among the Malays from different regions of the Peninsular is relatively similar, an observation, which is also shared by the population-based data from Singapore. ${ }^{45}$

There was no difference in prevalence of IBS between gender among the Malay population from the state of Kelantan, an observation, likewise being reported from hospital-based studies from India and Sri Lanka. ${ }^{46}$ The reasons for the equivalence in gender prevalence of IBS are unclear and require further studies. Red flags but not psychosocial alarms were commonly reported among subjects with IBS, and it was an independent predictor of IBS after multivariate analysis. Previous reports indicate that red flags have low yield for organic diseases after being investigated, ${ }^{47}$ and this was confirmed in our study subjects with investigated IBS, ${ }^{36}$ rather its presence was a surrogate for IBS if not diagnostic. However, changing red flags in particular elderly subjects 
above 50 years, necessitate further investigations, and this reiterates the importance of follow-up of patients having IBS with red flags. ${ }^{48}$

\section{Conclusion and Relevance to Management}

The ethnic Malays, in contrast to the Chinese and Indians, have different characteristics of dyspepsia. Organic causes of dyspepsia, including upper gastrointestinal cancers and erosive diseases, are uncommon among the Malays largely due to a low prevalence of $H$. pylori infection. This epidemiological observation questions the appropriateness of "test and treat $H$. pylori" strategy in this particular population, because it may not be as economical compared to the Chinese or the Indians. However, functional causes of dyspepsia including FD and IBS, are more common than expected in the Malays, and with EPS particularly being common, "empiric therapy with PPI" may be a more appropriate first management strategy rather than the "test and treat H. pylori" strategy. Further studies are needed to address this issues. There is equivalence in prevalence between gender, of which reasons are unclear, but males should be given similar attention as females to functional symptoms. Psychosocial alarm symptoms are common among the Malay subjects with FD, particularly among married females, and they should be referred for psychiatric evaluation if deemed necessary. In contrast, red flags are more common among Malay subjects with IBS, and even though they have low yield for organic diseases, nevertheless, they should be followed up regularly and assessed for any changing alarm features, which may necessitate further investigations.

\section{References}

1. Lee YY, Chua AS. Investigating functional dyspepsia in Asia. J Neurogastroenterol Motil 2012;18:239-245.

2. Bellwood P. Prehistory of the Indo-Malaysian Archipelago. 3rd ed. Canberra: ANU E Press 2007:69-95.

3. Omar AH. The encyclopedia of Malaysia: languages and literature. Singapore: Editions Didier Millet 2005:1-144.

4. Ghoshal UC, Singh R, Chang FY, et al. Epidemiology of uninvestigated and functional dyspepsia in Asia: facts and fiction. J Neurogastroenterol Motil 2011;17:235-244.

5. Mahadeva S, Yadav H, Rampal S, Everett SM, Goh KL. Ethnic variation, epidemiological factors and quality of life impairment associated with dyspepsia in urban Malaysia. Aliment Pharmacol Ther 2010;31:1141-1151.

6. Mahadeva S, Yadav H, Rampal S, Goh KL. Risk factors associated with dyspepsia in a rural Asian population and its impact on quality of life. Am J Gastroenterol 2010;105:904-912.

7. Mahadeva S, Yadav H, Everett SM, Goh KL. Economic impact of dyspepsia in rural and urban Malaysia: a population based study. J Neurogastroenterol Motil 2012;18:43-57.

8. Goh KL. Clinical and epidemiological perspectives of dyspepsia in a multiracial Malaysian population. J Gastroenterol Hepatol 2011; 26(suppl 3):35-38.

9. Bonne C, Hartz H, Klerks JV, Posthuma JH, Radsma W, Tjokronegoro S. Morphology of the stomach and gastric secretion in Malays and Chinese and the different incidence of gastric ulcer and cancer in these races. Am J Cancer 1938;33:265-279.

10. Siregar CD, Sinuhaji AB, Sutanto AH. Spectrum of digestive tract diseases 1985-1987 at the Paediatric Gastroenterology Outpatient Clinic of Dr. Pirngadi General Hospital, Medan. Paediatr Indones 1990;30:133-138.

11. Kang JY, Guan R, LaBrooy SJ, Lim KP, Yap I. The influence of sex, race and dialect on peptic ulcer and non-ulcer dyspepsia in Singapore. Ann Acad Med Singapore 1983;12:527-531.

12. Goh KL, Peh SC, Wong NW, Parasakhti N, Puthucheary SD. Campylobacter pylori infection: experience in a multiracial population. J Gastroenterol Hepatol 1990;5:277-280.

13. Goh KL, Parasakthi N. The racial cohort phenomenon: seroepidemiology of Helicobacter pylori infection in a multiracial South-East Asian country. Eur J Gastroenterol Hepatol 2001;13:177-183.

14. Uyub AM, Raj SM, Visvanathan R, et al. Helicobacter pylori infection in north-eastern peninsular Malaysia. Evidence for an unusually low prevalence. Scand J Gastroenterol 1994;29:209-213.

15. Raj SM, Lee YY, Choo KE, et al. Further observations in an area with an exceptionally low prevalence of Helicobacter pylori infection. Trans R Soc Trop Med Hyg 2008;102:1163-1164.

16. Rahim AA, Lee YY, Majid NA, et al. Helicobacter pylori infection among Aborigines (the Orang Asli) in the northeastern region of Peninsular Malaysia. Am J Trop Med Hyg 2010;83:1119-1122.

17. Farag TH, Stoltzfus RJ, Khalfan SS, Tielsch JM. Unexpectedly low prevalence of Helicobacter pylori infection among pregnant women on Pemba Island, Zanzibar. Trans R Soc Trop Med Hyg 2007;101: 915-922.

18. Sasidharan S, Uyub AM. Prevalence of Helicobacter pylori infection among asymptomatic healthy blood donors in Northern Peninsular Malaysia. Trans R Soc Trop Med Hyg 2009;103:395-398.

19. Lee YY, Mahendra Raj S, Graham DY. Helicobacter pylori infection A boon or a bane: lessons from studies in a low prevalence population. Helicobacter Published Online first: Apr 22 2013. doi: 10.111/hel.12058.

20. Lee YY, Ismail AW, Mustaffa N, et al. Sociocultural and dietary practices among Malay subjects in the north-eastern region of Peninsular Malaysia: a region of low prevalence of Helicobacter pylori infection. Helicobacter 2012;17:54-61.

21. Maran S, Lee YY, Xu S, et al. Toward understanding the low prevalence of Helicobacter pylori infection in Malays: genetic variants among Helicobacter pylori-negative ethnic Malays in the north-eastern region of Peninsular Malaysia and Han Chinese and South Indians. J Dig Dis 2013;14:196-202.

22. Maran S, Lee YY, Xu S, et al. Deleted in Colorectal Cancer (DCC) gene polymorphism is associated with $H$. pylori infection among susceptible Malays from the north-eastern region of Peninsular Malaysia. Hepatogastroenterology Published Online First: 25 Jul 
2012. doi: $10.5754 /$ hge 12471.

23. Lim GCC, Rampal S, Halimah Y. Cancer incidence in Peninsular Malaysia 2003-2005. Kuala Lumpur: National Cancer Registry 2007:80-82.

24. Yeh LY, Raj M, Hassan S, et al. Chronic atrophic antral gastritis and risk of metaplasia and dysplasia in an area with low prevalence of Helicobacter pylori. Indian J Gastroenterol 2009;28:49-52.

25. Maran S, Lee YY, Xu S, et al. Gastric precancerous lesions are associated with gene variants in Helicobacter pylori-susceptible ethnic Malays. World J Gastroenterol 2013;19:3615-3622.

26. Lee YY, Raj SM, Sharif SE, Salleh R, Ayub MC, Graham DY. Incidence of esophageal carcinoma among Malays in North-Eastern Peninsular Malaysia: an area with an exceptionally low prevalence of Helicobacter pylori infection. Dig Dis Sci 2011;56:1438-1443.

27. Lee YY, Tuan Sharif SE, Syed Abd Aziz SH, Raj SM. Barrett's Esophagus in an area with an exceptionally low prevalence of Helicobacter pylori Infection. ISRN Gastroenterol 2011;2011:394734. doi: 10.5402/2011/394734.

28. Ross IN, Nair S, Jayakumar CR. The incidence of upper gastro-intestinal disease in a Malaysian community. Singapore Med J 1985; 26:271-278.

29. Wu JC. Gastroesophageal reflux disease: an Asian perspective. J Gastroenterol Hepatol 2008;23:1785-1793.

30. Rosaida MS, Goh KL. Gastro-oesophageal reflux disease, reflux oesophagitis and non-erosive reflux disease in a multiracial Asian population: a prospective, endoscopy based study. Eur J Gastroenterol Hepatol 2004;16:495-501.

31. Mahadeva S, Goh KL. Clinically significant endoscopic findings in a multi-ethnic population with uninvestigated dyspepsia. Dig Dis Sci 2012;57:3205-3212.

32. Tack J, Talley NJ, Camilleri M, et al. Functional gastroduodenal disorders. Gastroenterology 2006;130:1466-1479.

33. Mahadeva S, Goh KL. Epidemiology of functional dyspepsia: a global perspective. World J Gastroenterol 2006;12:2661-2666.

34. Locke GR 3rd, Zinsmeister AR, Fett SL, Melton LJ 3rd, Talley NJ. Overlap of gastrointestinal symptom complexes in a US community. Neurogastroenterol Motil 2005;17:29-34.

35. Suzuki H, Hibi T. Overlap syndrome of functional dyspepsia and irritable bowel syndrome-are both diseases mutually exclusive? J Neurogastroenterol Motil 2011;17:360-365.
36. Lee YY, Waid A, Tan HJ, Chua SB, Whitehead WE. Validity and reliability of the Malay-language translation of the Rome III Diagnostic Questionnaire for irritable bowel syndrome. J Gastroenterol Hepatol 2012;27:746-750.

37. Suzuki H, Matsuzaki J, Hibi T. What is the difference between Helicobacter pylori-associated dyspepsia and functional dyspepsia? J Neurogastroenterol Motil 2011;17:124-130.

38. Jin X, Li YM. Systematic review and meta-analysis from Chinese literature: the association between Helicobacter pylori eradication and improvement of functional dyspepsia. Helicobacter 2007;12:541- 546.

39. Lee YY, Wahab N, Mustaffa N, et al. A Rome III survey of functional dyspepsia among the ethnic Malays in a primary care setting. BMC Gastroenterol 2013;13:84.

40. Abid S, Siddiqui S, Jafri W. Discriminant value of Rome III questionnaire in dyspeptic patients. Saudi J Gastroenterol 2011;17:129133.

41. Tan YM, Goh KL, Muhidayah R, Ooi CL, Salem O. Prevalence of irritable bowel syndrome in young adult Malaysians: a survey among medical students. J Gastroenterol Hepatol 2003;18:1412-1416.

42. Dong YY, Zuo XL, Li CQ, Yu YB, Zhao QJ, Li YQ. Prevalence of irritable bowel syndrome in Chinese college and university students assessed using Rome III criteria. World J Gastroenterol 2010;16: 4221-4226.

43. Rajendra S, Alahuddin S. Prevalence of irritable bowel syndrome in a multi-ethnic Asian population. Aliment Pharmacol Ther 2004;19: 704-706.

44. Lee YY, Waid A, Tan HJ, Chua AS, Whitehead WE. Rome III survey of irritable bowel syndrome among ethnic Malays. World J Gastroenterol 2012;18:6475-6480; discussion 6479.

45. Gwee KA, Wee S, Wong ML, Png DJ. The prevalence, symptom characteristics, and impact of irritable bowel syndrome in an Asian urban community. Am J Gastroenterol 2004;99:924-931.

46. Gwee KA, Lu CL, Ghoshal UC. Epidemiology of irritable bowel syndrome in Asia: something old, something new, something borrowed. J Gastroenterol Hepatol 2009;24:1601-1607.

47. Hammer J, Eslick GD, Howell SC, Altiparmak E, Talley NJ. Diagnostic yield of alarm features in irritable bowel syndrome and functional dyspepsia. Gut 2004;53:666-672.

48. Gwee KA, Bak YT, Ghoshal UC, et al. Asian consensus on irritable bowel syndrome. J Gastroenterol Hepatol 2010;25:1189-1205. 